\title{
PEMDAMPINGAN WANATANI DALAM KONSERVASI EX-SITU DUA VARIETAS GYRINOPS VERSTEEGII DI DESA PUSUK LESTARI, LOMBOK BARAT
}

\section{Wanatani Assistance In the Ex-Situ Conservation of Two Gyrinops Versteegii Variety In Pusuk Lestari Village, West Lombok District}

\author{
Tri Mulyaningsih*, Evy Aryanti, Aida Muspiah, Yuliadi Zamroni \\ ${ }^{1}$ Program Studi Biologi, Fakultas MIPA Universitas Mataram, \\ Jalan Majapahit Nomor 62 Kota Mataram Provinsi NTB, 83125 \\ *Alamat korespondesni : trimulya@unram.ac.id
}

(Tanggal Submission: 16 Juni 2020, Tanggal Accepted: 30 Agustus 2020)

\begin{abstract}
ABSTRAK
Pohon penghasil gaharu di pulau Lombok adalah jenis Gyrinops versteegii (Gilg.) Domke, (Thymelaeaceae), keberadaan di alam semakin terancam. Hal ini disebabkan tidak hanya perburuan liar tetapi juga terjadinya alih fungsi hutan alam menjadi kebun, perumahan dan lain-lainnya. Termasuk Kebun Induk Gaharu Pusuk, jumlah pohon gaharu semakin menyusut karena adanya perusakan batang, dicacah-cacah untuk mendapatkan gubal gaharu, perlakuan ini menyebabkan kematian. Untuk itu perlu adanya penataan kembali keberadaan pohon gaharu tersebut. Tujuan kegiatan ini adalah pemberdayaan wanatani dalam konservasi ex situ pohon penghasil gaharu di kawasan sekitar Kebun Induk Gaharu Pusuk, Lombok Barat. Hasil kegiatan pengabdian yang telah terlaksana adalah pembenihan sebanyak $1 \mathrm{~kg}$ buah ketimunan varietas soyun (G. versteegii var. tubuliformis) yang berisi 1000 butir biji. Buah ketimunan varietas pantai (G. versteegii var. longistipis) yang berisi 750 butir biji. Benih mulai berkecambah berumur 14 hari setalah tanam, dan prosentasi jumlah biji yang berkecambah sekitar $75 \%$. Pembuatan pembibitan dimulai pada akhir bulan Januari 2019 dan penanaman di lapangan setelah memasuki musim penghujan datang yaitu pada minggu ke tiga bulan Nopember 2019, di Kawasan sekitar Kebun Induk Gaharu, dengan jarak tanam 4mx4m.

Kata Kunci: konservasi ex situ, gaharu, Girinops versteegii, Lombok.

\section{PENDAHULUAN}

Kebun Induk Gaharu dibangun oleh Kanwil Kehutanan pada tahun 1998, di Dusun Pusuk Desa Lembahsari, Batulayar, Lombok Barat. Pada awalnya kebun hanya seluas 1 ha, selanjutnya diperluas hingga 40 ha. Kebun Induk Gaharu dibangun di kawasan hutan lindung, hal ini dimaksudkan agar pohon induk gaharu tersebut tidak dirusak dan

ditebang. Namun pada perkembangannya Pohon Induk gaharu yang relative utuh adalah kawasan yang ditanami pohon gaharu pertama kali. Pendirian Kebun Induk Gaharu ini dimaksudkan untuk melestarikan pohon gaharu yang ada di Lombok serta sebagai sumber benih gaharu. Pohon gaharu yang berada di Kebun Induk Gaharu Pusuk, Lombok Barat telah disertifikasi oleh Balai Sertifikasi Benih untuk tanaman Kehutanan yang berada di Bali.
\end{abstract}


Pohon gaharu yang tumbuh di pulau Lombok mempunyai nama lokal ketimunan (G.versteegii) adalah penghasil gaharu yang merupakan salah satu macam produk non kayu yang bernilai ekonomi tinggi. Pohon gaharu yang ditemukan di Pulau Lombok ada empat grup yakni Pantai grup (G. versteegiivar. longistipis), Beringin grup (G. versteegiivar. quadratus), Madu grup (G. versteegiivar. brevistipis) dan Soyun grup (G. versteegiivar. tubuliformis) dan Buaya grup (G. versteegiivar. brunniluteolus) (Mulyaningsih, et al, 2014, 2015, 2017a, 2017b; Iswantari et al, 2017).

Pohon gaharu di alam keberadaannya semakin terdesak, karena beralihnya fungsi hutan menjadi fungsi lain, seperti beralih fungsi ladang jagung seperti di beberapa kawasan di pulau Sumbawa dan Gorontalo, Sulawesi, beralih fungsi menjadi kebun kelapa sawit terjadi di Sumatera, Kalimantan, Sulawesi, dan Papua; beralih menjadi areal pertambangan, seperti di Sumatera (tambang batu bara), Kalimantan (batu bara dan emas), Lombok (tambang emas), Hamahera (tambang emas dan Nikel) dan papua (tambang emas).

Disamping habitatnya semakin sempit dan terdesak pohon gaharu masih mengalami penggerusan dengan adanya pencarian dan pembalakan liar di seluruh kawasan hutan Indonesia. Sejalan dengan hal tersebut akibatnya populasi dan jenis atau varietas gaharu alam juga akan mengalami penurunan jumlahnya. Seperti keberadaan pohon gaharu di pulau Lombok, Di hutan alam pada tahun 2009 pohon gaharu yang tersisa adalah pada tingkat pertumbuhan persemaian-pancang, pada tingkat pohon sudah tidak dapat ditemui terkecuali pada kawasan yang ada pemiliknya (Mulyaningsih, et al, 2017).

Pohon ketimunan tumbuh dengan baik pada ketinggian tempat antara 0-700 m dpl, lebih tinggi dari itu pertumbuhannya akan sedikit terhambat sehingga pohonnya tumbuh pada tingkat pertumbuhan perdu atau pancang. Pohon gaharu ini juga dapat tumbuh dengan pada tanah yang datar dan pada tanah yang mempunyai kemiringan hingga 45 o dengan $\mathrm{pH}$ tanah 5,8-7, dan $\mathrm{pH}$ tanah ini dapat menentukan jenis varietasnya. Pohon ketimunan juga memiliki pohon asosiasi yang sangat spesifik, seperti pohon Eugenia spp., pohon Aren, pohon, Sandoricum spp.dan lain-lain (Mulyaningsi, et al, 2015). Dengan melihat habitat pohon ketimunan yang tersebut di atas, maka Hutan lindung Pusuk sangat sesuai untuk pertumbuhan pohon ketimunan, sekaligus kawasan tersebut sebenarnya juga merupakan daerah persebaran alaminya.

\section{METODE KEGIATAN}

\section{Metode Pelaksanaan}

Program pendampingan masyarakat dilakukan secara aktif, dan intensif. Hal ini bertujuan untuk meningkatkan kreativitas masyarakat dalam merawat pohon gaharu yang ditanam dalam usaha untuk mengkonservasi pohon gaharu Gyrinops versteegii var. tubuliformis dan var. longistipis. Metode pelaksanaan program ini mengacu pada Giyantolin et al. (2019) dengan memodifikasi tambahan untuk program sesuai kondisi lingkungan Kelurahan Kenep, Sukoharjo yaitu sebagai berikut:

\section{Persiapan}

Pra pelaksanaan berisi kegiatan mengenai hal-hal yang disiapkan sebelum melakukan program.

a. Survei keberadaan pohon induk. Mencari keberadaan pohon induk G. versteegii var. tubuliformis dan var. longistipis yang sedang berbuah.

b. Persiapan sarana dan prasarana. Tahap ini mempersiapkan sarana dan prasarana yang mendukung kegiatan pengabdian masyarakat seperti: tempat untuk membuat bedengan yang digunakan sebagai hamparan tabur biji gaharu dan tempat yang digunakan untuk meletakan bibit dalam polibag. Bahan yang lain yaitu polybag, media tanam, bilah bambu untuk membatas barisan bibit dalam polybag, serta kardus untuk menyimpan buah gaharu. Alat yang disiapkan adalah pisau untuk mengupas buah gaharu, pacul untuk 
membuat bedengan/ guludan, gembor untuk menyiram persemaian bibit gaharu, parang dugunakan untuk membuat bilah bamboo yang diperuntukkan sebagai pembatas barisan bibit dalam polybag yang diatur dalam barisan.

\section{Pelaksanaan Kegiatan}

Kegiatan penanaman bibit pohon G. versteegii var. tubuliformis dan var. longistipis dimulai pada waktu memasuki musim penghujan di desa Pusuk Lestari yaitu pada tanggal 23 Nopember 2019.

\section{HASIL DAN PEMBAHASAN}

Kegiatan yang telah dilaksanakan ada meliputi Sepuluh tahapan kegiatanyang meliputi kegiatan:

1. Pencarian, pemilihan dan penetapan pohon induk $G$. versteegii var. tubuliformis dan var. longistipis.

2. Pemanenan dan memilihan buah $G$. versteegii var. tubuliformis dan var. longistipis.

3. Penyimpanan buah dan pengupasan biji.

4. Pembuatan rumah semai

5. Pembuatan bedengan atau guludan

6. Penyebaran biji pada pada bedengan dan pemeliharaan selama proses perkecambahan

7. Pemindahan semai ke polybag, pemilihan tempat pembibitan dan pengaturan polybag pada barisan.

8. Pemeliharaan bibit

9. Pelatihan arti penting konservasi pohon $G$. versteegii var. tubuliformis dan var. longistipis yang sudah tergolong langka dan cara penanaman.

10. Pemilihan tempat penanaman

11. Penanaman.

Setiap kegiatan melibatkan sekitar 10 mahasiswa yang ikut berpartisipasi. Hal ini dilakukan untuk melatih mahasiswa dalam aktifitas konservasi tumbuhan langka yang berada di
Lombok maupun di Indonesia dan melatih mahasiswa ikut bertanggungjawab dalam melestarikan tumbuhan langka/ terancam punah seperti pohon $G$. versteegii var. tubuliformis dan var. longistipis (Mulyaningsih, et al., 2014, 2015, 2017a dan 2017b).

\section{Kegiatan Pencarian, pemilihan dan penetapan pohon induk $G$. versteegii var. tubuliformis dan var. longistipis.}

Kedua varietas pohon tersebut di atas kebetulan berada di dalam Kawasan Kebun Induk Gaharu Pusuk. Pohon G. versteegii var. longistipis memiliki karakter kulit/ babakan yang berwarna krem kehijauan dengan spot-spot warna abu-abu. Babakan cukup tebal dan kuat (wulet). Buah memiliki stipes sepanjang hingga mencapai 1.5 kali Panjang kelopak bunga (kalix) yang mengawet, kulit mulus, mengkilat dan berbulu balig jarang pada ujung dan pangkal buah. Gubal gaharu yang terbentuk pada pinggirannya sering terdapat spot keputih-putihan, memiliki jumlah kromosom 2n 18, pada jaringan xylem memiliki jaringan interxilary phloem (Gambar 1) (mulyaningsih, et al., 2017; Iswantari, et al. 2017, Luo, et al, 2019).

Pohon G. versteegii var. tubuliformis memiliki karakter kulit/ babakan yang berwarna krem kemerah-merahan dengan spot-spot warna abu-abu atau warna hitam kemerah-merahan dengan spot abu-abu. Babakan relatif tipis dan melekat kuat pada jaringan kayu. Permukaan buah dop, dan bergelombang. Gubal gaharu yang terbentuk memiliki pola spiral dan terbentuknya gubal mengutuh pada suatu organ (Gambar 2).

\section{Kegiatan pemanenan dan memilihan buah $\mathbf{G}$.} versteegii var. tubuliformis dan var. longistipis. Musim berbuah bagi pohon $\mathrm{G}$. versteegii var. tubuliformis dan var. longistipis, biasanya satu kali setahun, kecuali pada pohon yang mempunyai habiantat dengan keberadaan air tanah yang berlimpah dapat menjadi 2 kali. Musim berbuah pada pohon ini terjadi pada bulan Desember atau pada bulan Juli. Pohon ini berbuah pada bulan Dderesember. Pemanen buah dilakukan dengan 
cara memilih buah-buah yang telah masak fiologis, ditandai warna kulit yang sudah berwarna kuning tua atau orange.

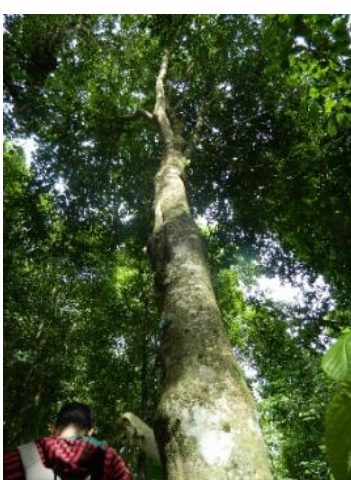

(a)

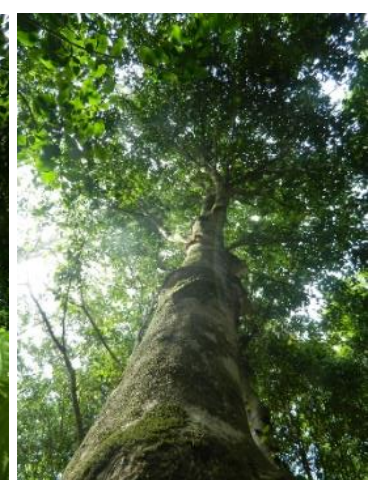

(b)
Gambar 1. Pohon: (a) G. versteegii var. longistipis, (b) pohon $G$. versteegii var. tubuliformis.

\section{Kegiatan penyimpanan buah dan pengupasan biji.}

Buah G. versteegii var. tubuliformis dan var. longistipis yang telah terseleksi disimpan di dalam dos dan disimpan selama satu minggu dalam ruang gelap pada suhu ruangan. Buah yang telah mengalami perubahan warna pada kulitnya, dari warna kuning tua menjadi coklat.Buah yang kulitnya menjadi coklat selanjutnya dikupas dan direndam kedalam air selama beberapa jam. Benih yang diperlakuan seperti di atas dihasilkan benih yang berkecambah mencapai $75 \%$ dan mulai berkecambah mulai 14 hari setelah tanam, sedangkan pada benih $\mathrm{G}$. walla yang tidak disimpan perkecambahan dapat mencapai $73,3 \%$, sedangkan benih yang disimpan 2-4 minggu pada suhu $80 \mathrm{C}$ benih yang berkecambah menurun hingga 26,6\% (de Alwis, 2016). Keberhasilan perkecambahan pada Aquilaria microcarpa dipengaruhi oleh media tanam, benih yang ditabur pada media pasir perkecambahan mencapai 76,67 dan media tanam yang merupakan campuran pasir:kompos $=1: 1$ perkecambahan meningkat menjadi $78,67 \%$, pada jenis pohon gaharu ini perkecambahan dimulai pada 7 hari setelah tanam, selama kelembaban tetap terjaga (Rayan, 2006).

\section{Kegiatan pembuatan rumah semai benih.}

Dalam pembuatan pembibitan tanaman penghasil gaharu termasuk pohon $\mathrm{G}$. versteegii var. tubuliformis dan var. longistipis, kondisi yang harus dipenuhi adalah kelembaban dan intensitas cahaya yang sangat rendah (Rayan, 2006; Prastyaningsih \& Azwin. 2017). Perkecambahan benih membutuhkan intensitas rendah di bawah $40 \%$ oleh karena itu perlu dibuatkan rumah benih/ atau penutup bedengan benih (Prastyaningsih \& Azwin. 2017). Pada kegiatan ini rumah benih dibuat dengan besaran intensitas cahaya antara 75-100 Lux. Dari perlakuan ini dihasilkan benih G. versteegii var. tubuliformis dan var. longistipis, yang berkecambah dapat mencapai $75 \%$.

\section{Kegiatan bedengan/gulutan tanah, penyebaran biji dan pemeliharaan selama proses perkecambahan.}

Bedengan / gulutan dibuat dengan ukuran panjang $x$ lebar $\times$ tinggi: $100 \mathrm{~cm} \times 75 \mathrm{~cm} \times 20 \mathrm{~cm}$, sebanyak 2 gulutan, satu benih $G$. versteegii var. tubuliformis dan yang lain untu benih $\mathrm{G}$. versteegii var. longistipis. Perawatan dalam persemaian benih tersebut adalh menjaga kelembaban media tanam, serta menjagadari gangguan hama.

\section{Kegiatan pemindahan semai ke polybag,} pemilihan tempat pembibitan dan pengaturan polybag pada barisan.

Pemindahan kecambah ke polybag dilakukan setelah kecambah memiliki dua daun. Polibag yang digunakan berukuran tinggixdiameter: $12 \mathrm{~cm} \times 9 \mathrm{~cm}$. Polibag yang telah terisi bibit diatur pada tempat yang cukup ternaung dan disusun dalam barisan dengan ukuran lebar $100 \mathrm{~cm}$ (berisi 14 polibag) dan panjang tergantung dari banyaknya jumlah bibit.

\section{Kegiatan Pemeliharaan bibit.}

Pemeliharaan bibit dalam polybag adalah penyiraman setiap hari minimal sekali dalam satu hari, bila tidak terjadi hujan. Selain itu penjagaan bibit dari serangan hama dan penyakit. Penyakit yang sering menyerang bibit pohon penghasil 
gaharu adalah busuk akar. Penyakit ini terjadi bila bibit sering terpapar hujan. Percikan air hujan sering membawa cendawan yang menyebabkan busuk akar. Oleh karena itu jika bibit pohon penghasil gaharu kehujanan perlu dilakukan penyiraman kembali menggunakan air sumur atau air PDAM untuk membersihkan percikan air hujan pada bibit tersebut. Hama yang sering menyerang bibit adalah belalang yang suka memakan daun bibit pohon penghasil gaharu. Karena jumlah bibit tidak banyak sehingga pemberantasan hama dilakukan secara manual, dengan cara menangkap belalang menggunakan jala.

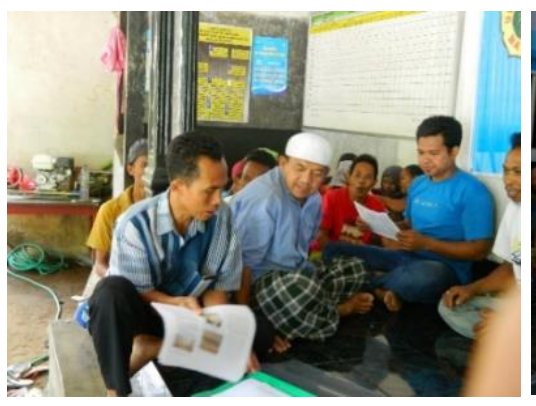

(a)

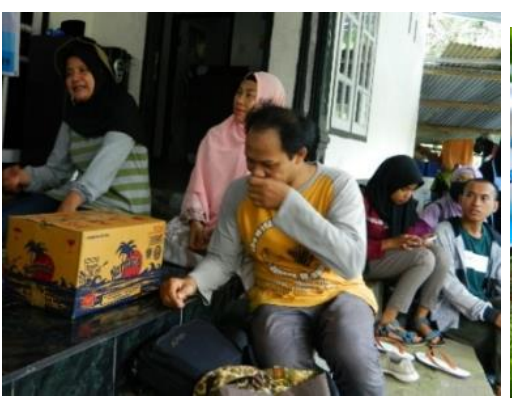

(b)

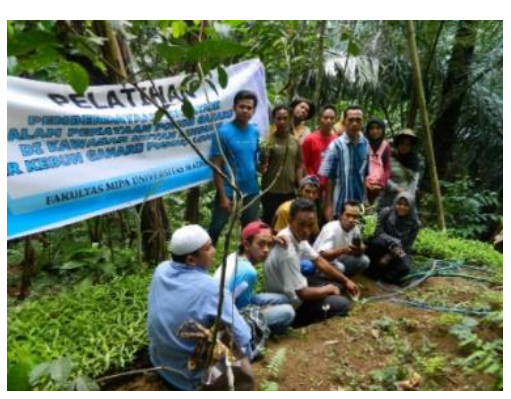

(c)

Gambar 2. Peserta pelatihan: (a) masyarakat wanatani desa Pusuk lestari, (b) tutor dan mahasiswa Prodi Biologi FMIPA Universitas Mataram, (c) masyarakat wanatani dan mahasiswa yang siap mau mengadakan penanaman bibit konservasi pohon $G$. versteegii var. tubuliformis dan var. longistipis.

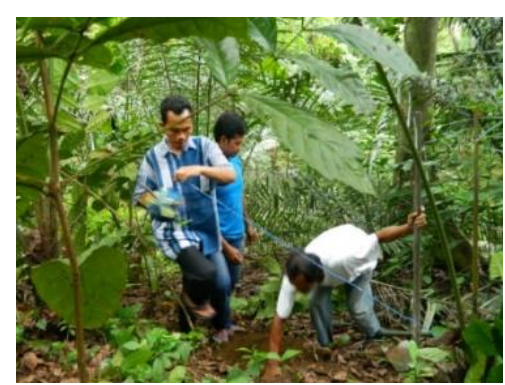

(a)

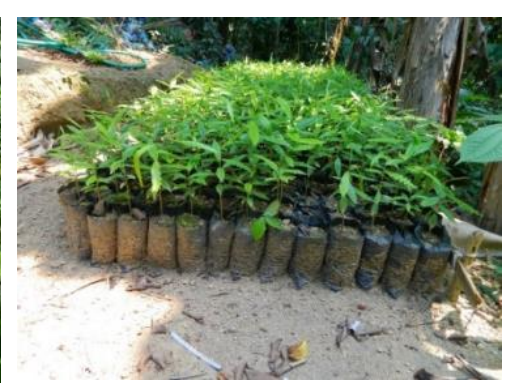

(b)

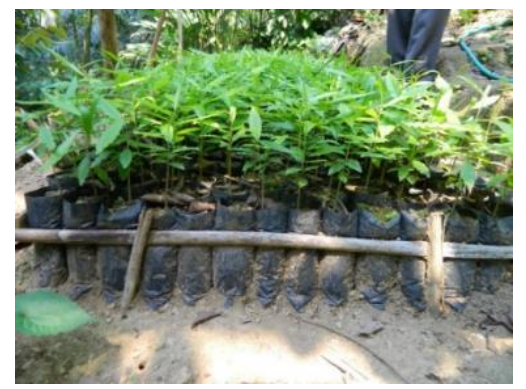

(c)

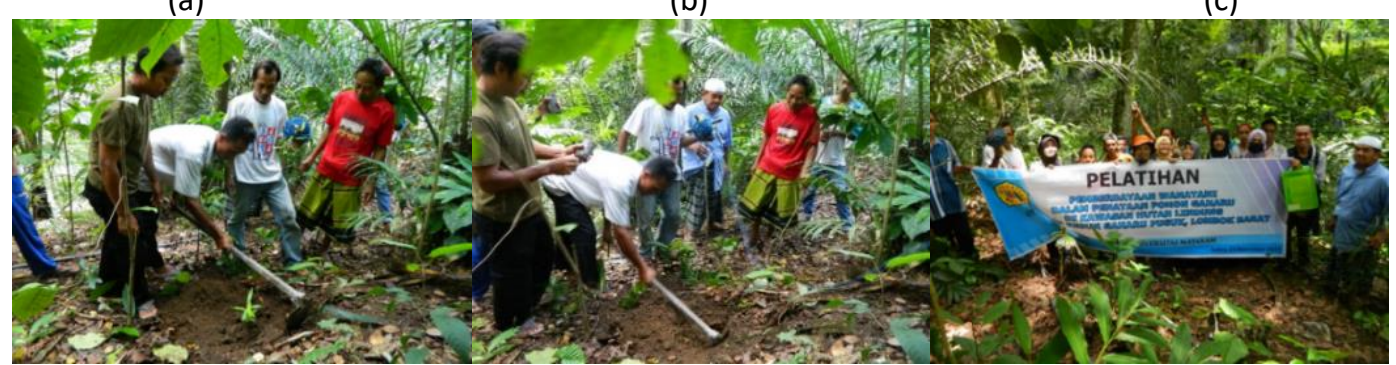

(d)

(e)

(f)

Gambar 3. Kegiatan penanaman bibit pohon G. versteegii var. tubuliformis dan var. Longistipis. (a) Bibit pohon G. versteegii var. Tubuliformis; (b) Bibit pohon G. versteegii var. Longistipis; (c) Pengukuran jarak tanam; (d) Pembuatan lubang tanam; (e) Penanaman bibit; (f) Peserta konservasi ex situ pohon G. versteegii var. tubuliformis dan var. Longistipis disekitar Kawasan Pohon Induk Gaharu, desa Pusuk Lestari Lombok Barat. 


\section{Kegiatan pelatihan arti penting konservasi pohon G. versteegii var. tubuliformis dan var. longistipis yang sudah tergolong langka dan cara penanaman.}

Pelatiahan ini penting dilakukan untuk memberi pencerahan arti penting konservasi ex situ pohon G. versteegii var. tubuliformis dan var. longistipis. Dimana pohon ini di hutan alam sudah sangat langka, sudah sangat sulit bahkan untuk sekarang ini tidak pernah ditemukan pohon penghasil gaharu yang mempunyai tingkat pertumbuhan hingga tingkat pohon di pulau lombok (Mulyaningsih, et al., 2015; 2017). Selain konservari ini berfungsi untuk melestarikan pohon tersebut yang telah terancam punah, juga sebagai penyedia benih yang lestari dan berfungsi sebagai agrowisata dan laboratorium lapangan untuk pohon penghasil gaharu.

\section{Kegiatan pemilihan tempat penanaman.}

Pemilihan tempat di sekitar kebun Induk Gaharu, hal ini disebabkan ada beberapa hal, antara lain: menambah variasi jenis dan varietas pohon penghasil gaharu di sekitar Kawasan tersebut. Pada Kawasan ini memiliki ketinggian tempat dan habitat yang ideal untuk pohon G. versteegii var. tubuliformis dan var. longistipis (Mulyaningsih, et al., 2015; 2017b; Mulyaningsih \& Yamada, 2008).

\section{Kegiatan Penanaman.}

Dalam penanaman bibit $\mathrm{G}$. versteegii var. tubuliformis dan var. longistipis, adalah pertama penyiapan bibit yang telah siap tanam (tinggi bibit telah mencapai $25 \mathrm{~cm}$, atau terlah membentuk percabangan). Berikutnya adalah membuat jarak tanam $4 m \times 4 m$ dan diteruskan dengan membuat lubang penanaman bibit yang berukuran panjangxlebarxdalam: $30 \mathrm{~cm} \times 30 \mathrm{~cm} \times 30 \mathrm{~cm}$. Bibit telah siap ditanam pada lubang bibit yang telah disiapkan.

\section{KESIMPULAN}

Dari hasil kegiatan pengabdian yang telah dilaksanakan adalah pembuatan pembenihan satu kilogram buah ketimunan varietas soyun (G. versteegii var. tubuliformis) yang berisi 1000 butir biji. Satu kilogram buah ketimunan varietas pantai (G. versteegii var. longistipis) yang berisi 750 butir biji. Benih mulai berkecambah berumur 14 hari setalah tanam, dan prosentasi jumlah biji yang berkecambah sekitar $75 \%$ (750 bibit G. versteegii var. Tubuliformis dan 563 bibit G. versteegii var. Longistipis). Pembuatan pembibitan dimulai pada akhir bulan Januari 2019 dan penanaman di lapangan setelah memasuki musim penghujan datang yaitu pada minggu ke tiga bulan Nopember 2019, di Kawasan sekitar Kebun Induk Gaharu, dengan jarak tanam $4 \mathrm{~m} \times 4 \mathrm{~m}$, di desa Pusuk Lestari, Lombok Barat.

\section{DAFTAR PUSTAKA}

De Alwis, H. N., Subangsinghe, S.M.C.U.P., \& Hettiarachchi, D.S. (2016). Effect of Storage Time and Temperature on Gyrinops walla Gaertn. Seed Germination. Journal of Environmental Professionals Sri Lanka, 5 (2): 16-24.

Giyantolin, Poerwanto, S. H., Hakim, A. I., Abustani, M., \& Wibowo, R. (2019). Pemberdayaan masyarakat hidup sehat bebas vektor nyamuk melalui konsep ecohealth village berbasis education for sustainable development. Riau Journal of Empowerment, 2(2): 61-69. https://doi.org/10.31258/raje.2.2.6169

Iswantari, W., Mulyaningsih, T., Muspiah, A. (2017). Karyomorfologi dan Jumlah Kromosom Empat Grup Gyrinops versteegii (Gilg.) Domke. di Lombok. Jurnal IImu Kehutanan, 11: 205-211.

Mulyaningsih, T., Marsono, D., Sumardi \& Yamada, I. (2014). Selection of Superior Breeding Infraspecies Gaharu of Gyrinops versteegii (Gilg) Domke. Journal of Agricultural Science and 
Technology. B 4: 485-492. URL:http://www.davidpublishing.com. Mulyaningsih, T., Marsono, D., Sumardi \& Yamada, I. (2015). Gyrinops versteegii (Gilg.) Domke. and the diversity of plant species associated in Western Lombok Forest. Proceeding: International seminar on the tropical natural resources 2015. "Towards sustainable utilization of the tropical natural resources for better human prosperity" pp. : 361-382. Mataram university Press.

Mulyaningsih, T., Marsono, D., Sumardi \& Yamada, I. (2017a). The presense of eaglewood Gyrinops versteegii in the natural forest of West Lombok Island, Indonesia. Journal of Ecology Environment and Conservation, 23(2): 723-729.

Mulyaningsih, T., Marsono, D., Sumardi \& Yamada, I. (2017b). Keragaman Infraspesifik Gaharu (Gyrinops versteegii (Gilg.) Domke) Di Pulau Lombok Bagian Barat. Journal Penelitian Hutan dan Konservasi Alam, 1: 57-66.

Mulyaningsih, T. \& Yamada, I. (2008). Notes on Some Species of Agarwood in Nusa Tenggara, Celebes and West Papua. Natural resource management and socio-economic transformation under the decentralization in Indonesia: Toward Sulawesi area studies. CSEAS. Kyoto University. Kyoto CSEAS. Kyoto University. Kyoto. Pp. 365-372.

Luo, B., Imai, T., Sugiyama, J., Marsoem, S. N., Mulyaningsih, T., Itoh, T. (2019). The occurrence and structure of radial sieve tubes in the secondary xylem of Aquilaria and Gyrinops. IAWA, Advance articles: 1-16. doi: https://doi.org/10.1163/2294193200002103.

Prastyaningsih, S.R. \& Azwin. (2017). The Growth of Agarwood Plants on the Different Canopy overs Level and Fertilizer in Oil Palm Plantation. International Conference on Environment and Technology (IC-Tech) 2017 IOP Publishing. IOP Conf. Series: Earth and Environmental Science 97: 012041. do i :10.1088/1755-1315/97/1/012041.

Rayan. (2006). Perlakuan Media Kecambah Terhadap Benih Tumbuhan Penghasil Gaharu (Aquilaria microcarpa) di Persemaian BP2KK Samarinda. Prosiding Seminar Bersama Hasil-Hasil Penelitian Balai Litbang Kehutanan Kalimantan, Balai Litbang Hutan Tanaman Indonesia Bagian Timur dan Loka Litbang Satwa Primata, Samarinda 12 April 2006, pp 240-245. 